\title{
Diazepam enhances the action but not the binding of the GABA analog, THIP
}

\author{
JOHN H. SKERRITT and ROBERT L. MACDONALD \\ Deparment of Neurology, University of Michigan Medical Center, Ann Arbor, MI 48109 1U.S.A.I
}

(Accepted November 29th, 1983)

Kev words: GABA receptors - diazepam - anticonvulsant - GABA agonists - spinal cord cultures

\begin{abstract}
GABA (4-aminobutyric acid) and its bicyclic analog THIP (4,5.6.7-tetrahydroisoxazolo-[4.5-c]-pyridin-3-ol) produced membrane hyperpolarization and increased chloride ion conductance of mouse spinal cord neurons in cell culture. Above 1 nM diazepam enhanced the actions of both GABA and THIP with similar potency and efficacy. Diazepam has been shown to enhance the binding of $\left[{ }^{3} \mathrm{H} \mid \mathrm{GABA}\right.$ to rat brain membranes over similar concentration ranges, with the $\mathrm{EC}_{90}$ values for enhancement of $\left.\mid{ }^{3} \mathrm{H}\right] \mathrm{GABA}$ binding and increase in membrane conductance being similar. In contrast, binding of [ $\left.{ }^{3} \mathrm{H}\right] \mathrm{THIP}$ has been shown to be unaltered by diazepam under a variety of conditions. The possible reasons for such a discrepancy between these electrophysiological and neurochemical results with THIP are discussed.
\end{abstract}

The inhibitory neurotransmitter, GABA, has a widespread distribution in the central nervous system, and multiple cellular actions of GABA, likely to arise from effects on GABA receptor subclasses, have been identified ${ }^{11}$. To develop GABA agonists with selective actions, certain GABA analogs of restricted conformation have been designed ${ }^{2.14}$. One key compound is THIP. a bicyclic GABA analog, which has potential therapeutic use since it had anticonvulsant and analgesic activity after oral administration to rodents ${ }^{10.14 .16}$.

Like GABA, THIP produced bicuculline-sensitive inhibition of firing of cat spinal interneurons and displaced $\left[{ }^{3} \mathrm{H}\right] \mathrm{GABA}$ binding to rat brain membranes with moderate potency $7.14,15$. However, important differences between THIP and GABA have been demonstrated. Although THIP was less potent than GABA in depolarizing isolated spinal fibers of the rat, the compound was 20 times stronger than GABA in depression of spinal synaptic activity2. GABA usually depolarized apical dendrites of hippocampal CAl pyramidal cells. while THIP has been shown to elicit hyperpolarizing responses exclusively'. Thus, it has been suggested that THIP may selectively activate a subclass of GABA receptors, possibly of syn- aptic rather than extrasynaptic localization 13 .

Diazepam enhanced the effects of synaptically released or exogenous GABA in a variety of central nervous system preparations ${ }^{4}$, including cultured mouse and chick spinal cord neurons ${ }^{\text {t.17}}$. Diazepam also has been shown to enhance [ ${ }^{3}$ [GABA binding to rat brain membranes ${ }^{x} 18.22 .23$. In neurochemical studies, however, anomalous interactions of diazepam and THIP have been documented. Unlike GABA. THIP failed to enhance [ $\left.{ }^{3} \mathrm{H}\right]$ diazepam binding at $4{ }^{\circ} \mathrm{C}$ and instead antagonized GABA-induced enhancement of benzodiazepine bindingt.13. While diazepam stimulated the binding of [ $\left.{ }^{3} \mathrm{H}\right] \mathrm{GABA}$ and $\left[{ }^{3} \mathrm{H}\right]$ muscimol to rat brain membranes. $\left.{ }^{3} \mathrm{H}\right] \mathrm{THIP}$ binding was unaltered by diazepam under a variety of incubation conditions ${ }^{23}$.

Using mouse spinal cord neurons in primary dissociated cell culture, we have investigated the postsynaptic actions of GABA and THIP and the effects of diazepam upon GABA and THIP responses. We report that both amino acids hyperpolarized neurons by increasing chloride ion conductance, the responses were picrotoxin-sensitive and the responses to both amino acids were enhanced with similar potency and to a similar extent by diazepam. We dem-

Correspondence: R. L. Macdonald. University of Michigan. Neuroscience Laboratory Building, 1103 East Huron. Ann Arbor, MI 48109 , U.S.A. 
A 1. KAC

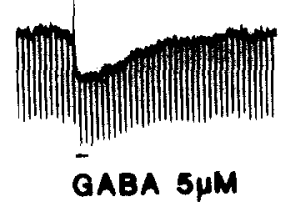

A2.

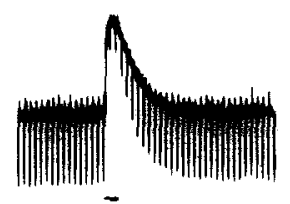

GABA BMM

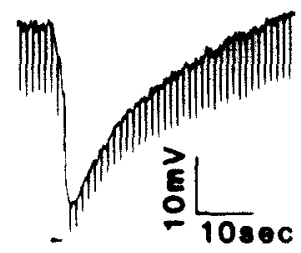

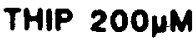

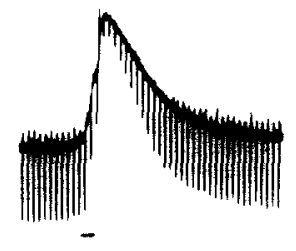

THIP 200pM
B1. GABA
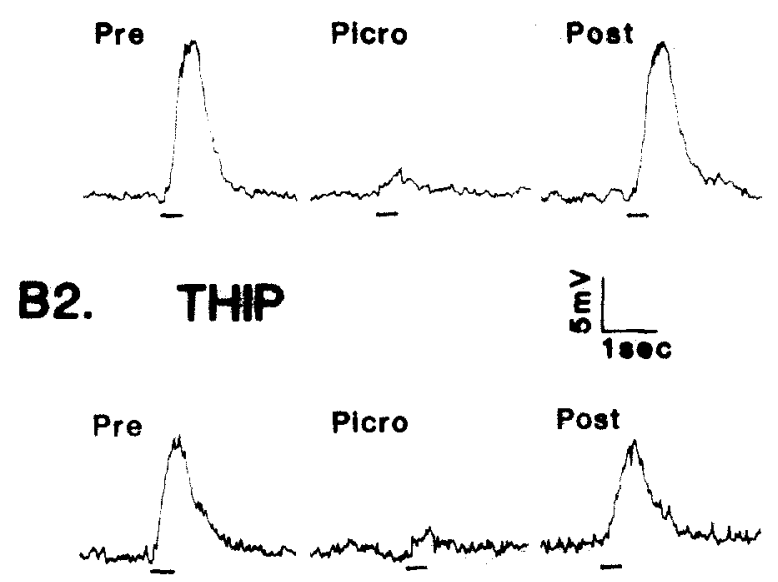

Fig. 1. GABA and THIP responses recorded from spinal cord neurons in cell culture. A: miniperfusion ( 2 s) with $5 \mu \mathrm{M} \mathrm{GABA}$ or 200 $\mu \mathrm{M}$ THIP increased membrane conductance and evoked hyperpolarizing responses during recordings with $4 \mathrm{M} K A c$-filled intracellular micropipettes $\left(A_{1}\right)$, and evoked depolarizing responses with $3 \mathrm{M} \mathrm{KCl-filled} \mathrm{intracellular} \mathrm{micropipettes}\left(A_{2}\right)$ : Resting membrane potentials were $-57 \mathrm{mV}$ and $-70 \mathrm{mV}$, respectively. B: picrotoxin $(100 \mu \mathrm{M})$ reversibly blocked the effects of iontophoretically applied GABA $\left(8 \mathrm{nA}, 400 \mathrm{~ms}, \mathrm{~B}_{1}\right)$ and THIP $\left(45 \mathrm{nA}, 400 \mathrm{~ms}, \mathrm{~B}_{2}\right)$ during recordings with $\mathrm{KCl}$-filled micropipettes. (Membrane hyperpolarized to $-90 \mathrm{mV}$.)

onstrate that enhancement of GABA responses and $\left[{ }^{3} \mathrm{H}\right] \mathrm{GABA}$ binding are similar in dose-dependency and discuss the possible reasons for difference in diazepam action on THIP responses and $\left[{ }^{3} \mathrm{H}\right]$ THIP binding.

Cell cultures were prepared from spinal cords with attached dorsal root ganglia from 12-14-day-old mouse embryos as described earlier ${ }^{21}$. Cultures were maintained for 5-8 weeks prior to electrophysiological experiments. Spinal cord neurons were penetrated under visual guidance on the modified stage of an inverted phase-contrast microscope, with high impedance (25-40 M $\Omega$ ) glass micropipettes filled with $4 \mathrm{M}$ potassium acetate (KAc) or $3 \mathrm{M}$ potassium chloride $(\mathrm{KCl})$. Impalements were accepted only if membrane potential was greater than $45 \mathrm{mV}$ and action potentials could be evoked.

Cultures were bathed in a phosphate-buffered saline containing elevated magnesium ions to suppress spontaneous activity (composition in $\mathrm{mM}: \mathrm{NaCl}$ 143.4, $\mathrm{KCl} 4.2, \mathrm{CaCl}_{2} 0.9, \mathrm{MgCl}_{2} 10.0$ and glucose 5.6 in $9.5 \mathrm{mM}$ sodium phosphate buffer at $\mathrm{pH} 7.35$ 7.40) and maintained at $33-34^{\circ} \mathrm{C}$ for electrophysiological experiments. Using a conventional bridge circuit, simultaneous current injection and membrane potential measurement were possible with a single recording micropipette; data were recorded on a 6-channel Gould polygraph.

GABA (0.5 M, pH 3.2) or THIP (0.2 M, pH 3.2) were applied iontophoretically using $400 \mathrm{~ms}$ duration rectangular current pulses $(+0.5-60 \mathrm{nA})$ at $4-\mathrm{s}$ intervals. GABA or THIP were also applied at known concentrations by miniperfusion using large (2-10 $\mu \mathrm{m})$ tip diameter micropipettes $(0.8$ psi ejection pressure, 2 s duration).

Diazepam or its vehicle $(0.01 \%$ or less dimethylsulfoxide) were applied by miniperfusion ( $0.2 \mathrm{psi}$ ejection pressure, $30 \mathrm{~s}$ duration) from a micropipette positioned $15-100 \mu \mathrm{m}$ from the soma of the cell under study. Such application of medium containing only $0.01 \%$ vehicle did not alter responses to iontophoretically applied GABA $(99.7 \pm 0.7 \%$ control, 6 cells $)$ or THIP $(98.6 \pm 2.8 \%$ control, 6 cells $)$. During assessment of diazepam action upon amino acid responses, cells were impaled with $3 \mathrm{M} \mathrm{KCl}$-containing micropipettes, and GABA or THIP were applied iontophoretically using constant current pulses. GABA and THIP responses of $6-9 \mathrm{mV}$ amplitude were evoked following membrane hyperpolarization to -80 to $-90 \mathrm{mV}$ and used for assessment of diazepam actions. Data were accepted only if the amino acid responses returned to control level within $5 \mathrm{~min}$ 
following removal of the diazepam-containing pipette from the vicinity of the cell under study. In most experiments diazepam effects on GABA and THIP responses were studied on the same cell, with 3 cycles of diazepam application possible.

When KAc recording micropipettes were used, application of GABA or THIP to spinal cord neurons rapidly and reversibly produced membrane hyperpolarization and an increase in membrane conductance (Fig. 1 $\mathrm{A}_{1}$ ). Use of $\mathrm{KCl}$-containing recording micropipettes allowed chloride ions to enter the cell, changing the equilibrium potential for chloride ions from about $-65 \mathrm{mV}$ to $-20 \mathrm{mV}^{19}$, and both GABA and THIP responses became depolarizing (Fig. $1 \mathrm{~A}_{2}$ ). At similar amplitudes. responses to THIP were of longer duration than those to GABA, applied either iontophoretically or by miniperfusion for similar durations (Fig. IA). In 21 cells for which GABA and THIP responses of approximately equal size (about $8 \mathrm{mV}$ ) were obtained following $400 \mathrm{~ms}$ iontophoretic applications (KCl-filled recording micropipettes), the mean duration at half-maximal amplitude of GABA responses was $0.47 \pm 0.02 \mathrm{~s}$ and of THIP responses was $0.66 \pm 0.12 \mathrm{~s}(P<0.001,2$-tailed Student's $t$ test). It has been suggested by others ${ }^{1}$ that the greater duration of THIP action may be due to the absence of active uptake mechanisms for this amino acid in neuronal tissue. Indeed, THIP does not inhibit [ $\left.{ }^{3} \mathrm{H}\right] \mathrm{GABA}$ uptake by minislices of rat cerebral cortex ${ }^{15}$ and $[3 \mathrm{H}]$ THIP is not itself accumulated by such slices (Skerritt, unpublished observations). However, the GABA uptake inhibitor, nipecotic acid $(200$ $\mu \mathrm{M})$. failed to increase the duration of responses to GABA recorded from spinal cord neurons in cell culture (unpublished observations). The longer duration of THIP responses could also arise from a greater mean chloride channel open time for THIP than GABA. However, noise analysis studies have actually revealed a shorter mean chloride channel open time for THIP than for GABA? Thus, the basis for the greater duration of THIP responses is uncertain.

Both GABA and THIP responses were virtually abolished in a reversible fashion by the GABA antagonist, picrotoxin $(100) \mu \mathrm{M})($ Fig. 1B). The actions of GABA and THIP have been shown also to be reversed by the GABA receptor antagonist, bicuculline. in the rat spinal cordt'.

The dose-dependencies of GABA and THIP re-

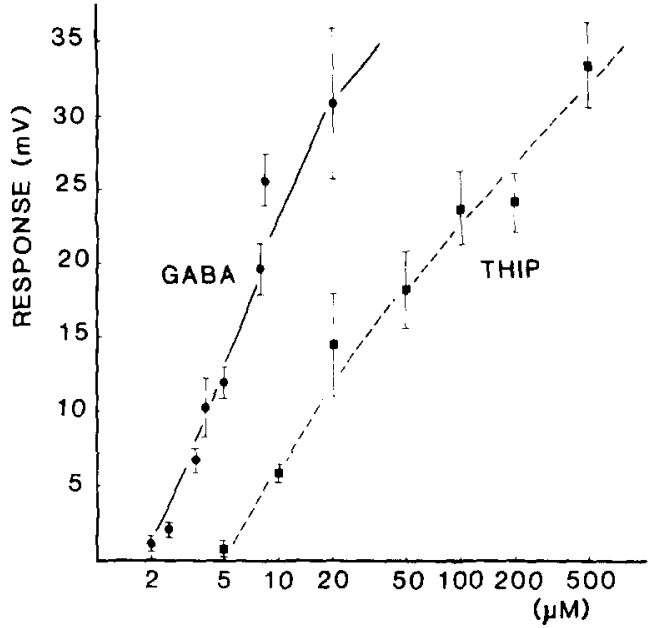

Fig. 2. Concentration-dependency of CiABA and THIP responses. Depolarizing responses were obtained following impalement of cells with $3 \mathrm{M} \mathrm{KCl}$-containing micropipettes and membrane hyperpolarization to -80 to $-90 \mathrm{mV}$. Responses at each concentration are averages of responses on $4-8$ cells. Bars indicate \pm standard error of the mean (S.E.M.). (Portions of the GABA data are from ref. 19.)

sponses were studied using miniperfusion and recording with $3 \mathrm{M} \mathrm{KCl-containing} \mathrm{micropipettes}$ (Fig. 2). Threshold for GABA responses was approximately $1-2 \mu \mathrm{M}$ and for THIP $5 \mu \mathrm{M}$. A $10 \mathrm{mV}$ depolarization was produced by approximately $4 \mu \mathrm{M}$ GABA and $16 \mu \mathrm{M}$ THIP. a $20 \mathrm{mV}$ depolarization was produced by about $8 \mu \mathrm{M}$ GABA and $60 \mu \mathrm{M}$ THIP and a $30 \mathrm{mV}$ depolarization was produced by $19 \mu \mathrm{M} \mathrm{GABA}$ and $350 \mu \mathrm{M}$ THIP. Thus, over the concentration range studied, GABA was 2.5-25 times more potent than THIP. THIP has been shown to be 3.9-fold less potent than GABA as an inhibitor of ['H]GABA binding to rat brain membranes". THIP has also been shown to be several-fold less potent than GABA in depolarization of ventral roots of neonatal rat spinal cordi and depolarization of apical dendrites of CAI hippocampal pyramidal cells'. The dose-response relationship for THIP was thus less steep than that for GABA (Fig. 2), but the slopes of $\log -\log$ plots of both GABA and THIP dose responsecurves are greater than 1.0, suggesting that both GABA and THIP bind cooperatively to receptors.

Diazepam $(1-1000 \mathrm{nM})$ enhanced the effects of iontophoretically applied GABA (Fig. 3. filled circles) and THIP (Fig. 3, open circles), while $0.1 \mathrm{nM}$ diazepam was ineffective. Maximal enhancement for both GABA and THIP occurred at $100 \mathrm{nM}$ and half- 


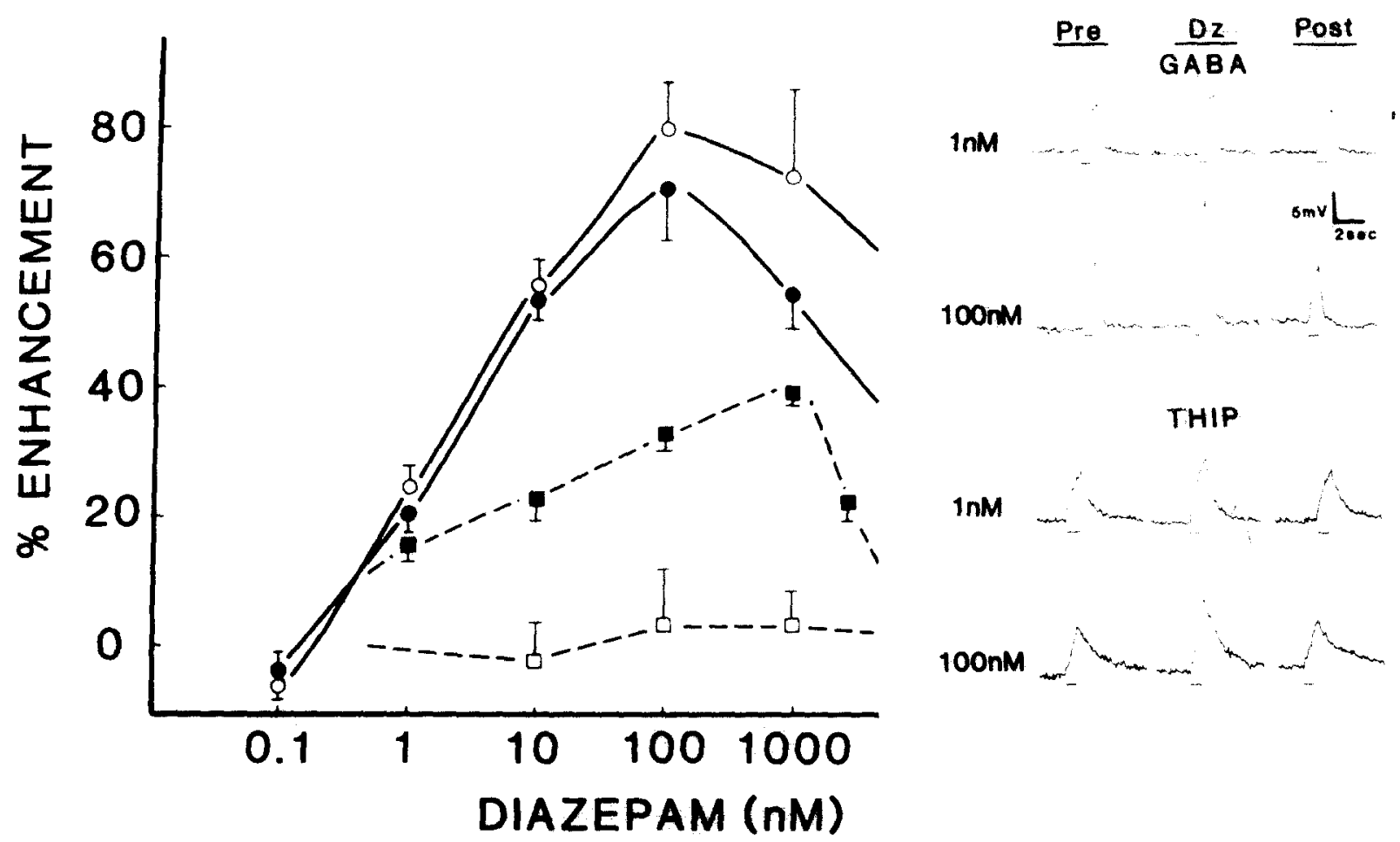

Fig. 3. Concentration-dependency of diazepam effects on GABA and THIP responses and on [ $\left.{ }^{3} \mathrm{H}\right] \mathrm{GABA}$ and $\left[{ }^{3} \mathrm{H}\right] \mathrm{THIP}$ binding (binding data from ref. 23). 6-15 cells were tested at each diazepam concentration, bars indicate \pm S.E.M. Filled circles and squares represent $\mathrm{GABA}$ response and binding, respectively, empty circles and squares represent THIP response and binding, respectively. Data shown at right were obtained on one cell $(\mathrm{MP}=-82 \mathrm{mV})$ for studies of the effects of $1 \mathrm{nM}$ diazepam on GABA and THIP responses (applied by iontophoresis, $\mathrm{KCl}$ recording) and another cell $(\mathrm{MP}=-80 \mathrm{mV}$ ) for $100 \mathrm{nM}$ diazepam.

maximal enhancement at $2.6 \pm 0.5 \mathrm{nM}(\mathrm{GABA})$ and $3.6 \pm 0.7 \mathrm{nM}$ (THIP) (THIP $\mathrm{EC}_{50}$ not significantly different from $\mathrm{GABA} \mathrm{EC}_{50}$ ). The concentration-dependencies of diazepam enhancement of GABA and THIP responses were strikingly similar, and at no diazepam concentration tested was there a statistically significant difference between the degree of enhancement of GABA and of THIP responses (Student's $t$-test). However, since we did not determine whether or not diazepam had comparable effects on GABA and THIP dose-response curves, we cannot be certain that the mechanism of enhancement was the same.

Diazepam (1-1000 $\mathrm{nM})$ also enhanced the binding of $\left[{ }^{3} \mathrm{H}\right] \mathrm{GABA}$ to fresh, washed synaptosomal membranes from rat brain ${ }^{22,23}$, but in contrast, did not enhance $\left[{ }^{3} \mathrm{H}\right]$ THIP binding under a variety of incubation conditions ${ }^{24}$. The concentration-dependency of enhancement of $\left[{ }^{3} \mathrm{H}\right] \mathrm{GABA}$ binding was quite similar to that of enhancement of $\mathrm{GABA}$ responses reported in this study with significant enhancement of $1 \mathrm{nM}$ di- azepam and $50 \%$ maximal enhancement at $4.6 \mathrm{nM}$. While peak enhancement of GABA responses occurred at lower concentrations than that of $\left[{ }^{3} \mathrm{H}\right] \mathrm{GABA}$ binding, it should be noted that the binding assays illustrated were incubated at $25^{\circ} \mathrm{C}$ and the electrophysiological experiments at $33-34{ }^{\circ} \mathrm{C}$; increases in the incubation temperature have been shown to decrease the $\mathrm{EC}_{50}$ of concentration-response curve for enhancement of [ $\left.{ }^{3} \mathrm{H}\right] \mathrm{GABA}$ binding by diazepam ${ }^{22}$. The similarities between the concentration-response relationship for diazepam enhancement of $\left[{ }^{3} \mathrm{H}\right] \mathrm{GABA}$ binding and enhancement of GABA action would suggest that the neurochemical results obtained with diazepam enhancement of $\left[{ }^{3} \mathrm{H}\right] \mathrm{GABA}$ binding are closely related to the effects of diazepam observed in various electrophysiological assays. A good correlation has also been shown between the degree of displacement of benzodiazepine binding in cerebral cortical cultures, and the concentration-dependency of enhancement of GABA actions by diazepam ${ }^{26}$. The disparity between diazepam effects, THIP action and 
binding raises the question of whether $\left[{ }^{3} \mathrm{H}\right]$ THIP and $\left[{ }^{3} \mathrm{H}\right] \mathrm{GABA}$ are binding to the same sites.

Binding studies with $\left[{ }^{3} \mathrm{H}\right]$ THIP suggest that the ligand labels sites with properties similar to $\left[{ }^{3} \mathrm{H}\right] \mathrm{GABA}$ binding sites. $\left[{ }^{3} \mathrm{H}\right]$ THIP binding was inhibited by a wide range of GABA analogs with a similar order of potencies to their inhibition of $\left[{ }^{3} \mathrm{H}\right] \mathrm{GABA}$ binding, and $\left[{ }^{3} \mathrm{H}\right] \mathrm{THIP}$, like $\left[{ }^{3} \mathrm{H}\right] \mathrm{GABA}$, labeled both higher and lower affinity sites in brain preparations ${ }^{7.24}$. However, the maximal binding capacity of the $\left[{ }^{3} \mathrm{H}\right]$ THIP sites was considerably lower than that of $\left[{ }^{3} \mathrm{H}\right] \mathrm{GABA}$, suggesting that $\left[{ }^{3} \mathrm{H}\right] \mathrm{THIP}$ labeled only a subclass of GABA receptors. In addition, the affinities of $\left[{ }^{3} \mathrm{H}\right] \mathrm{THIP}$ for its higher and lower affinity binding sites were greater than those of $\left[{ }^{3} \mathrm{H}\right] \mathrm{GABA}$. although the potency of THIP on spinal neurons in cell culture was found to be 2.5-25-fold lower than that of GABA. Under standard $\left[{ }^{3} \mathrm{H}\right] \mathrm{GABA}$ binding conditions (Tris-citrate buffer, $2^{\circ} \mathrm{C}$ ), the equilibrium dissociation constant $\left(K_{d}\right)$ of low affinity $\left[{ }^{3} \mathrm{H}\right] \mathrm{GABA}$ binding to washed synaptosomal rat brain membranes was $822 \mathrm{nM}^{23}$, near the threshold for GABA responses observed on spinal cord neurons in cell culture $(1-2 \mu \mathrm{M})$. However, the $K_{d d}$ value for [ $\left.{ }^{3} \mathrm{H}\right] \mathrm{THIP}$ was $331 \mathrm{nM}$, while the threshold for THIP responses was some 15 -fold higher $(5 \mu \mathrm{M})$.

Several explanations are possible for the discrepancy between the neurochemical and electrophysiological results obtained with THIP. Under a variety of conditions diazepam did not enhance the binding of $\left[{ }^{3} \mathrm{H}\right] \mathrm{THIP}$ to the lower affinity site found in brain membranes. It is possible that a THIP receptor of even lower affinity exists. The threshold for THIP actions in spinal cord neurons in cell culture was $5 \mu \mathrm{M}$, with larger depolarizations $(10 \mathrm{mV})$ requiring approximately $16 \mu \mathrm{M}$ THIP. Similarly, for enhancement of benzodiazepine binding (at $30{ }^{\circ} \mathrm{C}$ ), threshold effects occurred at $10 \mu \mathrm{M}$ THIP while the $\mathrm{EC}_{50}$ value was approximately $40 \mu \mathrm{M}^{25}$. Other workers'th have demonstrated the enhancement of the hy-

I Alger, B. E. and Nicoll. R. A., Pharmacological evidence for two kinds of GABA receptor on rat hippocampal pyramidal cells studied in vitro, J. Physiol. (Lond.), 328 (1982) 125-141.

2 Allan. R. D., Evans, R. H. and Johnston, G. A. R. . $\gamma$-Aminobutyric acid agonists: an in vitro comparison between depression of spinal synaptic activity and depolarization of spinal root fibres in the rat. Brit. J. Pharmacol., $70(1980)$ $609-615$ perpolarizing actions of a high THIP concentration $(50 \mu \mathrm{M})$ by $1 \mu \mathrm{M}$ diazepam in cultured cerebral cortical neurons. If a THIP receptor with a dissociation constant were to exist with a $K_{d}$ of $2(1-50) \mu \mathrm{M}$. such at site would not be detectable by conventional receptor binding methodologies that use a centrifugation or filtration means of separately bound and unbound radioligand due to the high dissociation rate expected for a site of such low atfinity. Whether such a site would be a third binding site for |:H|THIP. or is derived from the lower ( $331 \mathrm{nM})$ affinity site when binding is assayed under physiological conditions is unknown. The functions of the subclatses of $\mathrm{GABA}$ binding sites labeled by [ $\left.{ }^{3} \mathrm{H}\right]$ THIP and unaffected by benzodiazepines is unclear: possibly these sites may be involved in another known action of THIP. such as analgesia" $"$.

The finding that diazepam enhances THIP actions may be of possible clinical application. While both THIP and diazepam have potent anticonvulsant effects upon acute administration to mice, tolerance develops to the anti-epileptic activity of diazepans. and certain side effects (tremor. sedation. ataxia and dizziness) may prevent moderate doses of THIP being used in the clinical setting2". Since the enhancement of THIP effects by diazepam could lead to a synergistic rather than purely additive anticonvulsant effect of the two compounds, clinical testing of low dose combinations of THIP and benzodiazepine may prove worthwhile.

We thank Professor Graham Johnsion, Dr. Powl Krogsgaard-Larsen and Dr. Mary Ann Werc for their advice. J.H.S. is a recipient of an award from the Rotary Foundation of Rotary International and the research was supported by NSF Grant 019722 and NIH Grants NS 00408 and NS 19692 to R.I.M. We wish to acknowledge the gifts of diazepam (Hoffman-La Roche. Nutley, NJ) and THIP (Lundbeck. Copenhagen. Denmark).

3 Barker. J. I... MacDonald, J. F., Mathers, D. A., McBur ney, R. N. and Oertel, W. GABA receptor functons in cultured mouse spinal neurons. In F. V. De Fudis and $P$. Mandel (Eds.), Amino Acid Neurotransmatlers, Ratven Press, New York. 1981, pp. 281-293.

4 Braestrup. C.. Nielsen. M. Krogsgatard-Larsen, P'. and Falch, E.. Partial agonists for brain CABA/henzodiazepine receptor complex. Nature (Lond.), 28(1) (1979) 331-333.

5 Browne, T. R. and Penry, J. K. Benzodiazepines in the 
treatment of epilepsy, Epilepsia, 14 (1973) 277-310.

6 Choi, D. W., Farb, D. H. and Fishbach, G. D., Chlordiaze poxide selectively augments GABA action in spinal cord cell cultures, Nature (Lond.), 269 (1977) 342-344.

7 Falch, E. and Krogsgaard-Larsen, P., The binding of the specific GABA agonist $\left[{ }^{3} \mathrm{H}\right]$ THIP to rat brain synaptic membranes, J. Neurochem., 38 (1982) 1123-1129.

8 Guidotti, A., Toffano, G. and Costa, E., An endogenous protein modulates the affinity of GABA and benzodiazepine receptors in rat brain, Nature (Lond.), 275 (1978) 553-555.

9 Haefely, W., Pieri, L., Polc, P. and Schaffner, R., General pharmacology and neuropharmacology of benzodiazepine derivatives, Handb. Exp. Pharmacol., 55 (II) (1981) 13-283.

10 Hill, R. C., Maurer, R., Buescher, H. H. and Roemer, R. Analgesic properties of the GABA-mimetic THIP, Europ. J. Pharmacol., 69 (1981) 221-224.

11 Johnston, G. A. R., GABA receptors. In J. B. Lombardini and A. D. Kenny (Eds.), The Role of Peptides and Amino Acids as Neurotransmitters, Alan R. Liss, New York, 1981. pp. 1-17.

12 Johnston, G. A. R., Allan, R. D., Kennedy, S. M. E. and Twitchin, B., Systematic study of GABA analogues of restricted conformation. In P. Krogsgaard-Larsen, J. ScheelKruger and $\mathrm{H}$. Kofod (Eds.), GABA-Neurotransmitters, Munksgaard, Copenhagen, 1978, pp. 149-164.

13 Karobath, M., Placheta, P., Lippitsch, M. and KrogsgaardLarsen, $P$., Is stimulation of benzodiazepine receptor binding mediated by a novel GABA receptor? Nature (Lond.), 278 (1979) 748-749.

14 Krogsgaard-Larsen, P., Johnston, G. A. R., Lodge, D. and Curtis, D. R., A new class of GABA agonist, Nature (Lond.), 268 (1977) 53-55.

15 Krogsgaard-Larsen, P. and Johnston, G. A. R., Structureactivity studies on the inhibition of GABA binding to rat brain membranes by muscimol and related compounds, $J$. Neurochem., 30 (1978) 1377-1382.

16 Llovd, K. G. and Morselli, P. L.. Potential anticonvulsants-
GABA receptor agonists. In D. M. Woodbury, J. K. Penry and C. E. Pippenger (Eds.), Antiepileptic Drugs, Raven Press, New York, 1982, pp. 839-858.

17 Macdonald, R. L. and Barker, J. L., Benzodiazepines specifically modulate GABA-mediated postsynaptic inhibition in cultured mammalian neurons, Nature (Lond.), 271 (1978) 563-564.

18 Meiners, B. A. and Salama, A. I., Enhancement of benzodiazepine and GABA binding by the novel anxiolytic, tracazolate, Europ. J. Pharmacol., 78 (1982) 315-322.

19 Nowak, L. M., Young, A. B. and Macdonald, R. L., GABA and bicuculline actions on mouse spinal cord and cortical neurons in cell culture, Brain Research, 244 (1982) 155-164.

20 Petersen, H. R., Jensen, I. and Dam, M., THIP: a single blind controlled trial in patients with epilepsy, Acta neurol. scand., 67 (1983) 114-117.

21 Ransom, B. R., Neale, E., Henkart, M., Bullock, P. N. and Nelson, P. G., Mouse spinal cord cells in culture. 1 . Morphologic and intrinsic neuronal electrophysiological properties, J. Neurophysiol., 40 (1977) 1132-1150.

22 Skerritt, J. H., Chen Chow, S. and Johnston, G. A. R.. Differences in the interactions between $\mathrm{GABA}$ and benzodiazepine binding sites, Neurosci. Lett., 33 (1982) 173-178.

23 Skerritt, J. H., Willow, M. and Johnston, G. A. R., Diazepam enhancement of low affinity GABA binding to rat brain membranes, Neurosci. Lett, 29 (1982) 63-66.

24 Skerritt, J. H. and Johnston, G. A. R., Diazepam stimulates the binding of GABA and muscimol but not THIP to rat brain membranes, Neurosci. Lett., in press.

25 Supavilai. P. and Karobath, M., The effect of temperature and chloride ions on the stimulation of $\left[{ }^{3} \mathrm{H}\right]$ flunitrazepam binding by the muscimol analogues THIP and piperidine-4sulfonic acid, Neurosci. Lett., 19 (1980) 337-341.

26 White, W. F., Dichter, M. A. and Snodgrass, S. R., Benzodiazepine binding and interactions with the GABA receptor complex in living culture of rat cerebral cortex, Brain Research, 215 (1981) 162-176. 